\title{
BMJ Open Early life risk factors of motor, cognitive and language development: a pooled analysis of studies from low/middle- income countries
}

\begin{abstract}
Ayesha Sania, ${ }^{1}$ Christopher R Sudfeld, ${ }^{2}$ Goodarz Danaei, ${ }^{3}$ Günther Fink, ${ }^{4}$ Dana C McCoy, ${ }^{5}$ Zhaozhong Zhu, ${ }^{6}$ Mary C Smith Fawzi, ${ }^{7}$ Mehmet Akman, ${ }^{8}$ Shams E Arifeen, ${ }^{9}$ Aluisio J D Barros, ${ }^{10}$ David Bellinger, ${ }^{11}$ Maureen M Black, ${ }^{12}$ Alemtsehay Bogale, ${ }^{13}$ Joseph M Braun, ${ }^{14}$ Nynke van den Broek, ${ }^{15}$ Verena Carrara, ${ }^{16}$ Paulita Duazo, ${ }^{17}$ Christopher Duggan, ${ }^{18}$ Lia C H Fernald, ${ }^{19}$ Melissa Gladstone,${ }^{20}$ Jena Hamadani, ${ }^{9}$ Alexis J Handal, ${ }^{21}$ Siobán Harlow, ${ }^{22}$ Melissa Hidrobo, ${ }^{23}$ Chris Kuzawa, ${ }^{24}$ Ingrid Kvestad, ${ }^{25}$ Lindsey Locks, ${ }^{26}$ Karim Manji, ${ }^{27}$ Honorati Masanja, ${ }^{28}$ Alicia Matijasevich, ${ }^{29}$ Christine McDonald, ${ }^{30}$ Rose McGready, ${ }^{31,32}$ Arjumand Rizvi, ${ }^{33}$ Darci Santos, ${ }^{34}$ Leticia Santos, ${ }^{34}$ Dilsad Save, ${ }^{35}$ Roger Shapiro, ${ }^{36}$ Barbara Stoecker, ${ }^{37}$ Tor A Strand (i) , ${ }^{38}$ Sunita Taneja, ${ }^{39}$ Martha-Maria Tellez-Rojo, ${ }^{40}$ Fahmida Tofail, ${ }^{41}$ Aisha K Yousafzai, ${ }^{2}$ Majid Ezzati, ${ }^{42}$ Wafaie Fawzi ${ }^{43}$
\end{abstract}

To cite: Sania A, Sudfeld CR, Danaei G, et al. Early life risk factors of motor, cognitive and language development: a pooled analysis of studies from low/middle-income countries. BMJ Open 2019;9:e026449. doi:10.1136/ bmjopen-2018-026449

- Prepublication history and additional material for this paper are available online. To view these files, please visit the journal online (http://dx.doi. org/10.1136/bmjopen-2018026449).

Received 02 September 2018 Revised 15 August 2019 Accepted 16 August 2019

Check for updates

(c) Author(s) (or their employer(s)) 2019. Re-use permitted under CC BY-NC. No commercial re-use. See rights and permissions. Published by BMJ.

For numbered affiliations see end of article.

Correspondence to

Dr Ayesha Sania;

ays328@mail.harvard.edu

\section{ABSTRACT}

Objective To determine the magnitude of relationships of early life factors with child development in low/middleincome countries (LMICs).

Design Meta-analyses of standardised mean differences (SMDs) estimated from published and unpublished data.

Data sources We searched Medline, bibliographies of key articles and reviews, and grey literature to identify studies from LMICs that collected data on early life exposures and child development. The most recent search was done on 4 November 2014. We then invited the first authors of the publications and investigators of unpublished studies to participate in the study.

Eligibility criteria for selecting studies Studies that assessed at least one domain of child development in at least 100 children under 7 years of age and collected at least one early life factor of interest were included in the study.

Analyses Linear regression models were used to assess SMDs in child development by parental and child factors within each study. We then produced pooled estimates across studies using random effects meta-analyses. Results We retrieved data from 21 studies including 20882 children across 13 LMICs, to assess the associations of exposure to 14 major risk factors with child development. Children of mothers with secondary schooling had $0.14 \mathrm{SD}(95 \% \mathrm{Cl} 0.05$ to 0.25$)$ higher cognitive scores compared with children whose mothers had primary education. Preterm birth was associated with 0.14 SD $(-0.24$ to -0.05$)$ and 0.23 SD $(-0.42$ to -0.03$)$ reductions in cognitive and motor scores, respectively. Maternal short stature, anaemia in infancy and lack of access to clean water and sanitation had significant negative associations with cognitive and motor

\section{Strengths and limitations of this study}

- Pooling data from 21 studies, this study provides the most comprehensive analysis of early life risk factors of child development in low/middle-income countries.

- The study cohorts were selected from 13 countries across the globe.

- Uniform classifications of early life exposures and statistical analyses applied across studies.

- Fourteen major risk factors-parental, environmental and nutritional factors are included.

- Data on important risk factors such as exposure to environmental neurotoxicants, responsive parenting behaviors and child stimulation were not available.

development with effects ranging from -0.18 to -0.10 SDs.

Conclusions Differential parental, environmental and nutritional factors contribute to disparities in child development across LMICs. Targeting these factors from prepregnancy through childhood may improve health and development of children.

\section{INTRODUCTION}

More than 250 million children under age 5 years in low/middle-income countries (LMICs) are at risk of not attaining their full development potential. ${ }^{1-3}$ The first 1000 days (from conception through 24 months of age) is critical for children's development, as the plasticity of the rapidly developing brain 


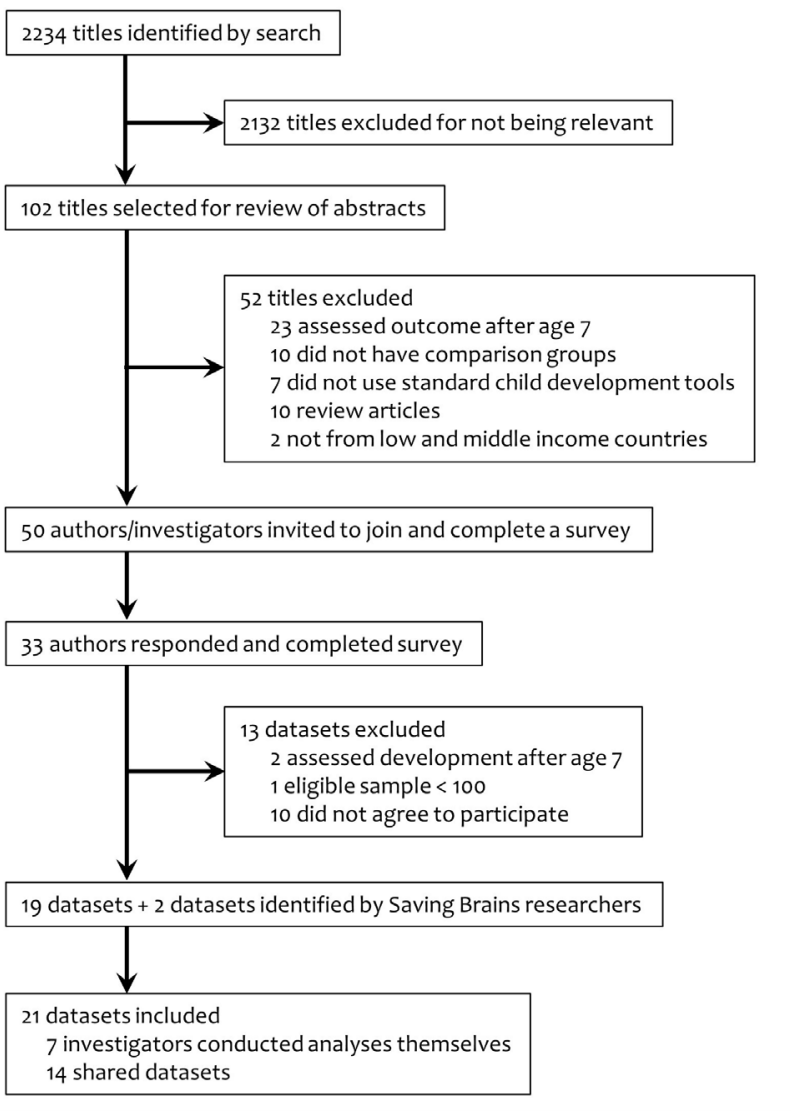

Figure 1 Flowchart of study selection.

makes it vulnerable to harmful exposures as well as receptive to positive stimuli during this period. ${ }^{45}$ Suboptimal development in early childhood may have long-term detrimental effects on education ${ }^{6}$ and income attainment, ${ }^{7}$ which in turn contribute to poverty and inequality across the lifecycle, and possibly also across generations. ${ }^{8}$ Disadvantaged children with developmental deficits lose an estimated $19.8 \%$ of adult income yearly, ${ }^{9}$ with an estimated global cost of US $\$ 177$ billion for physical growth delays alone. ${ }^{10}$ In recognition of the high burden and cost associated with early life disadvantage, the 2030 sustainable development goals (SDGs) directly target early childhood development (ECD) under SDG $4,{ }^{11}$ which calls for ensuring access to quality ECD care and preprimary education for all children.

The relative importance of exposures to nutritional, socioeconomic and environmental risk factors in early life on different domains of child development in LMICs is poorly understood. Studies systematically reviewing the evidence linking early life risk factors to child outcomes primarily focused on growth (eg, stunting), ${ }^{9}{ }^{12}$ identifying iodine deficiency, iron deficiency anaemia, intrauterine growth restriction, maternal depression, exposure to violence, HIV infection as risk factors, and cognitive stimulation, maternal education, breast feeding as protective factors. ${ }^{1314}$ However, the independent pathways from these risks to cognitive, motor and language development are not fully elucidated yet. ${ }^{15} 16$ Consequently, priority risk factors and interventions for improving cognitive, language and motor development may differ from those designed to improve physical development in LMICs.

To determine the magnitude of the relationships linking early life exposures with child development in LMICs, we pooled data from 21 studies conducted in LMICs. We then examined the associations of early life risk factors on cognitive, motor and language development among children aged $<7$ years across studies. These pooled observational estimates are intended to inform the design of individual and packaged intervention studies to promote early child development in LMICs.

\section{METHODS \\ Study identification}

We searched Medline, bibliographies of key articles and reviews, and grey literature to identify datasets from LMICs that collected data on early life exposures and child development. Search terms included a list of risk factors, terms related to motor, cognitive, language and socioemotional development, and a list of LMICs (list of search terms, online supplementary appendix 1). The most recent search was done on 4 November 2014. We also identified additional datasets via communication with researchers of published studies that were not retrieved in our search. The primary criterion for inclusion of the datasets was the assessment of at least one domain of child development (cognitive, motor, language and socioemotional) using a standard child development assessment instrument in at least 100 children before 7 years of age, as well as the collection of at least one early life factor of interest as part of the study.

Following identification of the potential datasets, we contacted 50 first authors of the publications and investigators of unpublished studies, of whom $33(66 \%)$ responded to participate in the present study (figure 1). We asked researchers to complete a survey that included questions about child development assessment tools used, age of developmental assessment and details on the early life factors measured in their study. Following the survey, 10 investigators declined to participate, 2 studies were excluded as the eligible sample size was $<100$ and 1 study was excluded as development was assessed after age 7 years. The investigators then shared results of predefined analyses on their data or shared data with researchers at the Harvard T H Chan School of Public Health to complete the analyses of individual studies and the meta-analyses.

\section{Early life factors}

We created a list of early life risk factors based on the review of the current literature. ${ }^{13} 14$ These risk factors are represented in the 'Good Health' and 'Adequate Nutrition' components of nurturing care framework for ECD proposed by the WHO. ${ }^{17}$ We enquired about the availability of data on a list of risk factors in the preliminary survey sent to the investigators. Based on the 
survey responses, we then selected 14 early life factors that were available in at least four datasets to include in the pooled analyses. Following the standard definitions of categories used in published studies and the survey responses on how individual studies recorded data on each risk factors, we used uniform categorization of the risk factors applicable to all datasets. Risk factors were grouped into parental factors: father's education and mother's education (categories for each variable: none $<1$ year; primary 1 to $<6$ years; secondary 6 to $<10$ years; higher $\geq 10$ years $)$, maternal age $(<15,15$ to $<20,20$ to $<35, \geq 35$ years $)$, maternal height $(<145,145$ to $<150$, 150 to $<155,>155 \mathrm{~cm}$ ) maternal body mass index (BMI; $<18.5,18.5$ to $<25,25$ to $<30, \geq 30 \mathrm{~kg} / \mathrm{m}^{2}$ ), haemoglobin level during pregnancy (normal $\geq 110 \mathrm{~g} / \mathrm{L}$; mild anaemia 100-109g/L ; moderate anaemia 70-99g/L) and child factors: birth weight (low birth weight $<2500 \mathrm{~g}$; moderate low 2000-2500 g; very low birth weight $<2000 \mathrm{~g}$ ), preterm birth (preterm $<37$ weeks; late preterm $34-37$ weeks; early preterm $<34$ weeks), small for gestational age (SGA; $<10$ percentile; moderate SGA 3 to $<10$ percentile; severe SGA $<3$ percentile) as determined by Alexander and Oken standards, exclusive breast feeding until 6 months of age, haemoglobin levels in infancy (normal $\geq 110 \mathrm{~g} / \mathrm{L}$; mild anaemia $100-109 \mathrm{~g} / \mathrm{L}$; moderate anaemia $70-99 \mathrm{~g} / \mathrm{L}$ ), access to clean water (yes, no), access to sanitation (yes, no) and diarrhoea preceding the 6 months before development assessment (yes, no). Details on the definition and categories of the risk factors are included in online supplementary appendix 2. We also enquired about data on birth spacing, maternal HIV infection, malaria, intimate partner violence and depression, but a limited number of studies had data on these factors.

\section{Outcomes}

We included cognitive, motor and language outcomes in the analyses, socioemotional outcomes were not measured in a sufficient number of studies. If a study measured child development on multiple occasions, we included the measurement obtained at the age closest to 24 months. Since different tools were used for development assessment across studies, all development scores were standardised (z-scored) to ensure comparability between the measurements in different studies.

\section{Analyses of individual studies}

Within each study, linear regression models were used to assess standardised mean differences (SMDs) in cognitive, motor and language scores for the selected risk factors. Multivariable models were adjusted for child's age and sex, maternal education and a measure of socioeconomic status (eg, household income or wealth index). Maternal education was adjusted as a confounder in all models except for the model that estimated the effects of maternal education. If a study was a randomised trial, intervention assignment was also included in the adjusted model. In addition, estimates for preterm birth and gestation-specific birth weight category (SGA and appropriate-for-gestational-age) were adjusted for each other. The missing indicator method was used for covariates when $<10 \%$ of the data were missing; if $>10 \%$ were missing the covariate was excluded from the analyses.

\section{Meta-analysis}

Meta-analysis for a given risk factor was conducted if estimates from at least four studies were available. To account for the variation in tools used for measuring development, we only pooled the means and SEs of the standardised outcomes scores. As multivariable adjustment substantially changed the effect estimates, we used the adjusted effect estimates for meta-analysis. Given that heterogeneous effects seemed likely across the large variety of contexts studied, random effects meta-analysis was conducted using the DerSimonian and Larid method. ${ }^{18}$ Heterogeneity was assessed using $\mathrm{I}^{2}$ statistics. All analyses were conducted using the metaan commands in Stata V.12.0.

\section{Patient and public involvement \\ Patients and or public were not involved.}

\section{RESULTS}

Table 1 shows the characteristics of the studies included in the analyses. We included 21 datasets with developmental measurements on 20882 children of which 8 were from Asia, ${ }^{19-26} 7$ were from sub-Saharan Africa, ${ }^{27-33}$ 5 were from Latin America and 1 from Europe. ${ }^{34-39}$ The majority of studies $(n=18)$, including 12 randomised trials, ${ }^{19-23} 262730-3339$ followed up the participants prospectively. The Bayley Scales of Infant and Toddler Development (BSID) was used to assess child development in most of the studies with, BSID-III administered in five studies, ${ }^{24}{ }^{27} 31-33$ BSID-II in five studies ${ }^{19-2230}$ and BSID-I in one study. ${ }^{39}$ The Ages and Stages Questionnaire was used in wo studies, ${ }^{23} 37$ and a few studies used local adaptations of standard tools. ${ }^{29}{ }^{36}$ The majority of the studies had data on both motor and cognitive development, ${ }^{19-25}$ 27-39 one study had data on motor development only ${ }^{26}$ and six studies provided data on language development. ${ }^{29}$ 31-34 Development was assessed before age 2 years in most studies, ${ }^{19-27}$ 29-35 3839 except for three studies that assessed development at ages between 3 and 6 years. ${ }^{28} 3637$

\section{Parental factors}

Pooled estimates for the association of parental factors with child cognitive, motor and language development are presented in table 2. Higher attained maternal education was associated with improved cognitive, motor and language development scores. Children whose mothers attended or completed secondary school had 0.14 SD (95\% CI 0.05 to 0.25 ), 0.12 SD (95\% CI 0.06 to 0.18 ) and $0.13 \mathrm{SD}$ (95\% CI 0.04 to 0.21 ) higher cognitive, motor and language scores, respectively, as compared with children whose mothers only had primary school education. Compared with children of mothers with 
Table 1 Characteristics of the included studies

\begin{tabular}{|c|c|c|c|c|c|c|c|}
\hline & Study & Setting & $\begin{array}{l}\text { Primary study } \\
\text { design }\end{array}$ & Study population & $\begin{array}{l}\mathbf{N} \\
\text { (data on child } \\
\text { development) }\end{array}$ & $\begin{array}{l}\text { Child development tool } \\
\text { used }\end{array}$ & $\begin{array}{l}\text { Child age } \\
\text { in years at } \\
\text { assessment } \\
\text { (mean } \pm S D \text { ) }\end{array}$ \\
\hline 1 & $\begin{array}{l}\text { Black } \\
(2004)^{19}\end{array}$ & Bangladesh & $\begin{array}{l}\text { Randomised } \\
\text { controlled trial }\end{array}$ & Birth cohort & 221 & $\begin{array}{l}\text { Bayley Scales of Infant } \\
\text { and Toddler Development, } \\
\text { 2nd edition (BSID-II) and } \\
\text { the Home Observation } \\
\text { for Measurement of the } \\
\text { Environment (HOME) } \\
\text { Inventory }\end{array}$ & $1.06 \pm 0.03$ \\
\hline 2 & $\begin{array}{l}\text { Tofail } \\
(2008)^{20}\end{array}$ & Bangladesh & $\begin{array}{l}\text { Randomised } \\
\text { controlled trial }\end{array}$ & Birth cohort & $\begin{array}{l}2853 \text { total }(2116 \\
\text { tested) }\end{array}$ & $\begin{array}{l}\text { Two problem-solving tests, } \\
\text { motor index of Bayley } \\
\text { Scales of Infant and Toddler } \\
\text { Development, } 2 \text { nd edition } \\
\text { (BSID-II) and Wolke's } \\
\text { behaviour ratings }\end{array}$ & $0.61 \pm 0.02$ \\
\hline 4 & $\begin{array}{l}\text { Taneja } \\
(2005)^{22}\end{array}$ & India & $\begin{array}{l}\text { Randomised } \\
\text { placebo- } \\
\text { controlled trial }\end{array}$ & $\begin{array}{l}\text { Prospective, } \\
\text { community-based } \\
\text { cohort }\end{array}$ & 571 & $\begin{array}{l}\text { Bayley Scales of Infant and } \\
\text { Toddler Development, 2nd } \\
\text { edition (BSID-II) }\end{array}$ & $1.25 \pm 0.16$ \\
\hline 5 & $\begin{array}{l}\text { Kvestad } \\
(2015)^{23}\end{array}$ & India & $\begin{array}{l}\text { Randomised } \\
\text { placebo- } \\
\text { controlled trial }\end{array}$ & $\begin{array}{l}\text { Prospective, } \\
\text { community-based } \\
\text { cohort }\end{array}$ & 422 & $\begin{array}{l}\text { Ages and Stages } \\
\text { Questionnaire, 3rd edition } \\
\text { (ASQ-3) }\end{array}$ & $1.37 \pm 0.60$ \\
\hline 6 & $\begin{array}{l}\text { Yousafzai } \\
(2014)^{24}\end{array}$ & Pakistan & $\begin{array}{l}\text { Community- } \\
\text { based cluster- } \\
\text { randomised } \\
\text { effectiveness trial }\end{array}$ & $\begin{array}{l}\text { Prospective, } \\
\text { community-based } \\
\text { cohort }\end{array}$ & 1357 & $\begin{array}{l}\text { Bayley Scales of Infant and } \\
\text { Toddler Development, 3rd } \\
\text { edition (BSID-III) }\end{array}$ & $11.6 \pm 0.83$ \\
\hline
\end{tabular}

Sub-Saharan Africa

\begin{tabular}{|c|c|c|c|c|c|c|c|}
\hline 9 & $\begin{array}{l}\text { Shapiro } \\
(2013)^{27}\end{array}$ & Botswana & $\begin{array}{l}\text { Randomised } \\
\text { controlled trial }\end{array}$ & $\begin{array}{l}\text { Prospective, } \\
\text { community-based } \\
\text { cohort }\end{array}$ & 224 & $\begin{array}{l}\text { Bayley Scales of Infant and } \\
\text { Toddler Development, 3rd } \\
\text { edition (BSID-III) }\end{array}$ & $2.03 \pm 0.08$ \\
\hline 10 & $\begin{array}{l}\text { Bogale } \\
(2009)^{28}\end{array}$ & Ethiopia & $\begin{array}{l}\text { Cross-sectional } \\
\text { study }\end{array}$ & $\begin{array}{l}\text { Cross-sectional, } \\
\text { community-based } \\
\text { cohort }\end{array}$ & 100 & $\begin{array}{l}\text { Raven's Coloured } \\
\text { Progressive Matrices (CPM) } \\
\text { and Kaufman Assessment } \\
\text { Battery for Children-II (KABC- } \\
\text { II) }\end{array}$ & $5.11 \pm 0.24$ \\
\hline 12 & $\begin{array}{l}\text { McDonald } \\
(2013)^{30}\end{array}$ & Tanzania & $\begin{array}{l}\text { Randomised } \\
\text { placebo- } \\
\text { controlled trial }\end{array}$ & Birth cohort & 305 & $\begin{array}{l}\text { Bayley Scales of Infant and } \\
\text { Toddler Development, 2nd } \\
\text { edition (BSID-II) }\end{array}$ & $1.28 \pm 0.04$ \\
\hline
\end{tabular}




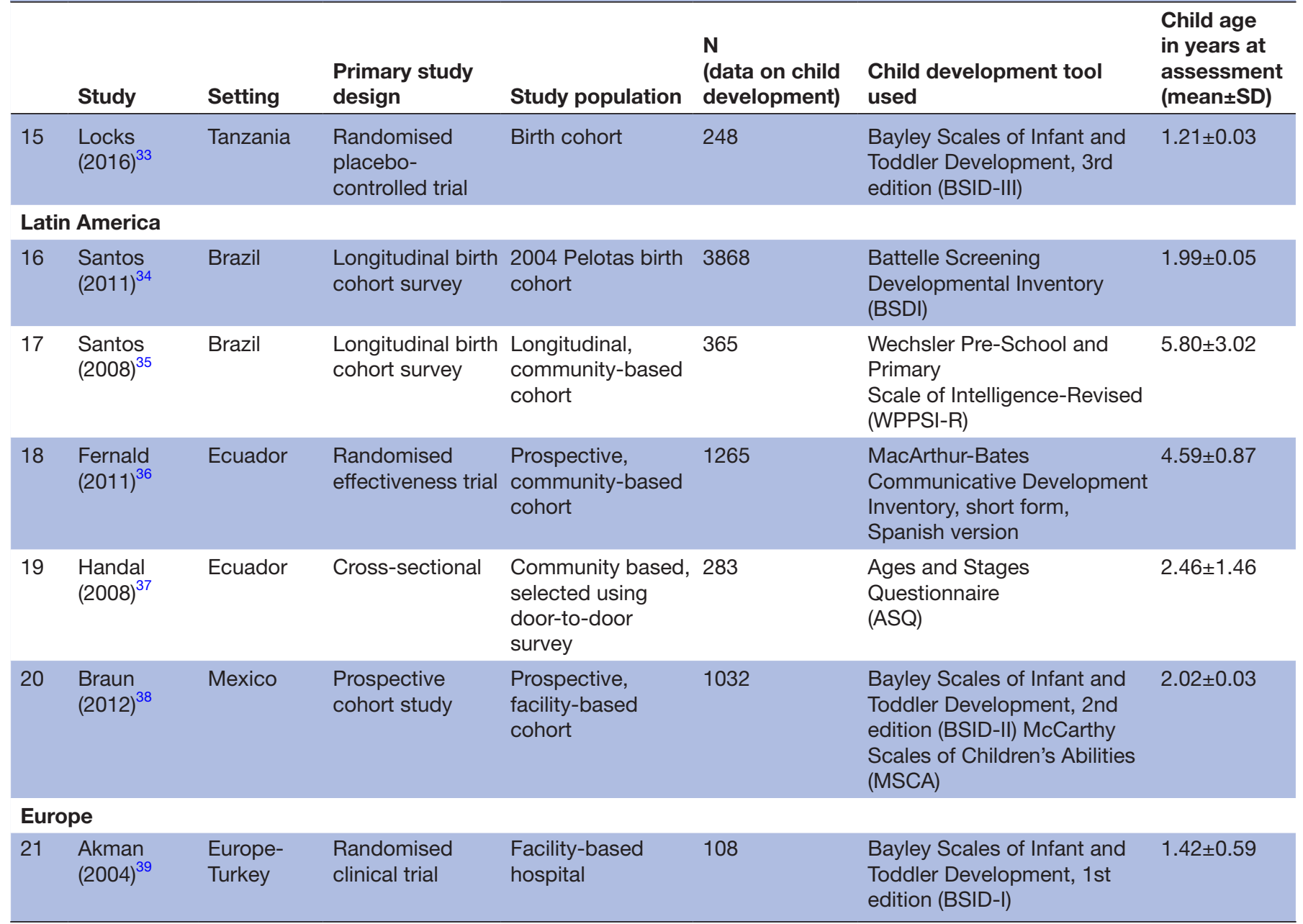

primary education, children of mothers with $\geq 10$ years of education scored $0.36 \mathrm{SD}(95 \%$ CI 0.19 to 0.48$), 0.26 \mathrm{SD}$ (95\% CI 0.14 to 0.38 ) and $0.21 \mathrm{SD}(95 \%$ CI 0.09 to 0.33 ) higher in cognitive, motor and language scores, respectively. Children of mothers with no formal schooling scored lowest in cognitive, motor and language scores. There was a significant positive association between father's education and cognitive and motor development after adjusting for maternal education, although the magnitude of the effect sizes was smaller than for those of maternal education. We found no significant relationships between maternal age at birth and cognitive, motor or language development.

Children of mothers with short stature (height $<155 \mathrm{~cm}$ ) tended to have lower cognitive, motor and language scores as compared with a maternal height $>155 \mathrm{~cm}$. Children whose mothers were $<145 \mathrm{~cm}$ scored $0.10 \mathrm{SD}(95 \% \mathrm{CI}$ -0.20 to 0.004$), 0.11 \mathrm{SD}(95 \% \mathrm{CI}-0.19$ to 0.03$)$ and 0.11 SD $(95 \%$ CI -0.31 to 0.09$)$ lower on cognitive, motor and language development, respectively. Low maternal BMI $\left(<18.5 \mathrm{~kg} / \mathrm{m}^{2}\right)$ was significantly associated with lower cognitive development scores (SD: -0.10 ; $95 \%$ CI -0.19 to 0.02 ), but not motor or language development. There was no significant association of maternal haemoglobin with child cognition.

\section{Child factors}

Pooled estimates for the association of child factors with development are presented in table 3. Compared with children born with normal birth weight, children born with low birth weight $(<2500 \mathrm{~g})$ had significantly poorer cognitive and motor scores. Children with birth weights $<2000 \mathrm{~g}$ had on average $0.27 \mathrm{SD}(95 \% \mathrm{CI}-0.49$ to 0.07 ) lower cognitive, $0.26 \mathrm{SD}(95 \% \mathrm{CI}-0.40$ to 0.12$)$ lower motor and $0.28 \mathrm{SD}(95 \% \mathrm{CI}-0.60$ to 0.05$)$ lower language scores, compared with normal birth weight children $(\geq 2500 \mathrm{~g})$. Compared with term and appropriate for gestational age (AGA) infants, preterm-AGA infants had $0.14 \mathrm{SD}(95 \% \mathrm{CI}-0.24$ to 0.05$)$ and $0.23 \mathrm{SD}(95 \% \mathrm{CI}$ -0.42 to 0.03 ) lower cognitive and motor scores, respectively. Term-SGA infants had poorer developmental scores in some studies, but the pooled effect estimates for term-SGA, adjusted for preterm birth, were not statistically significant.

Anaemia in infancy was significantly and negatively associated with both motor and cognitive development 
scores. Combined effect sizes of moderate anaemia were -0.18 SD (95\% CI -0.27 to 0.09 ) for motor and -0.11 SD (95\% CI -0.12 to 0.10) for cognitive scores. Compared with children residing in households with access to clean water, children without access had $0.10 \mathrm{SD}$ (95\% CI -0.12 to 0.09$)$ lower cognitive and $0.07 \mathrm{SD}(95 \% \mathrm{CI}-0.16$ to 0.01$)$ lower motor and $0.15 \mathrm{SD}(95 \% \mathrm{CI}-0.35$ to 0.05$)$ lower language scores. Children without access to clean sanitation had 0.13 SD (95\% CI - 0.18 to 0.07 ) lower cognitive and 0.10 SD (95\% CI -0.19 to 0.01$)$ lower motor scores. In the pooled analyses, exclusive breast feeding until 6 months of age and diarrhoea during the preceding 6 months of development assessment did not have significant associations with either cognitive or motor development.

Figures 2 and 3 present effect sizes of all risk factors included in the analyses. Forests plots of metanalysis of individual risk factors are included in online supplementary appendix 2, Figures 1-86.

\section{DISCUSSION}

This pooled analysis of development assessment of 20882 children from 21 LMIC studies determined that low maternal and paternal education, short maternal stature, low birth weight, preterm birth, anaemia in infancy and lack of access to clean water and sanitation were associated with lower child development scores among children $<7$ years of age. We did not find significant associations of maternal anaemia, fetal growth restriction, exclusive breast feeding or childhood diarrhoea with development scores.

We observed a dose-response relationship between parental education and child development. While a large body of literature supports the consistent role of maternal education in promoting children's language and cognitive developments, evidence on the role of paternal education is more limited. ${ }^{354041}$ Recent reports suggest advanced language and cognitive development among children of more educated fathers that persisted after adjustment for family income and mothers' education. ${ }^{42}$ Maternal education is associated with more warm, responsive and stimulating home environments, which in turn are predictive of more positive developmental outcomes for children. ${ }^{43}$ High maternal education is also linked with protective factors like good feeding and hygiene practices and frequent utilisation of antenatal care and child immunisation. ${ }^{445}$ In addition, low maternal education is associated with known risk factors of poor child development such as malnutrition in children, and depression and stress in mothers. ${ }^{46}{ }^{47}$ Although prior work suggests that less educated mothers tend to be less receptive to ECD messages, research also shows that their children may benefit more from ECD interventions. ${ }^{48}$ Therefore, adopting a two-generational intervention approach to empower parents and improve parenting capacity are likely to generate long-term benefits for child development. Due to the availability of maternal education data, 


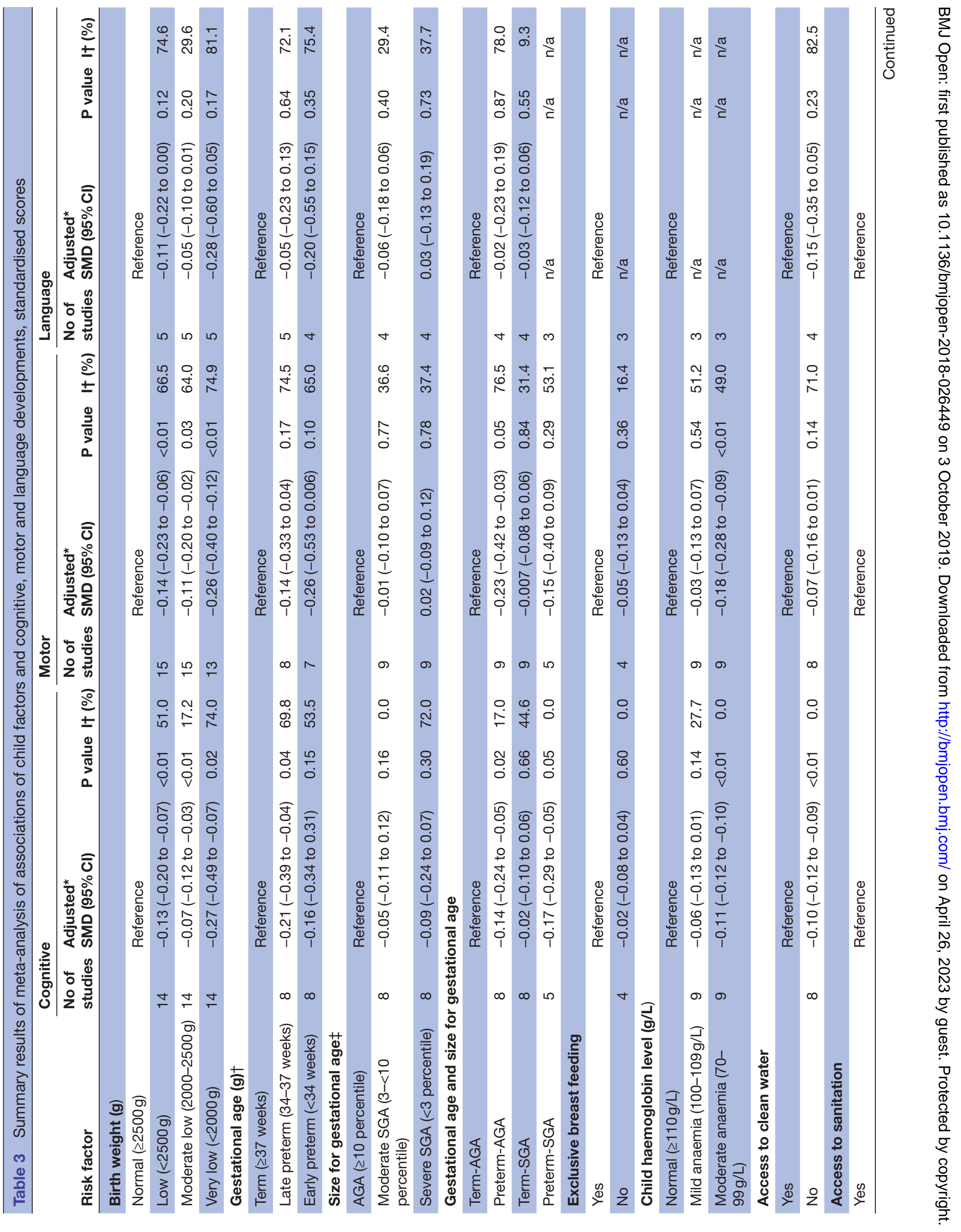




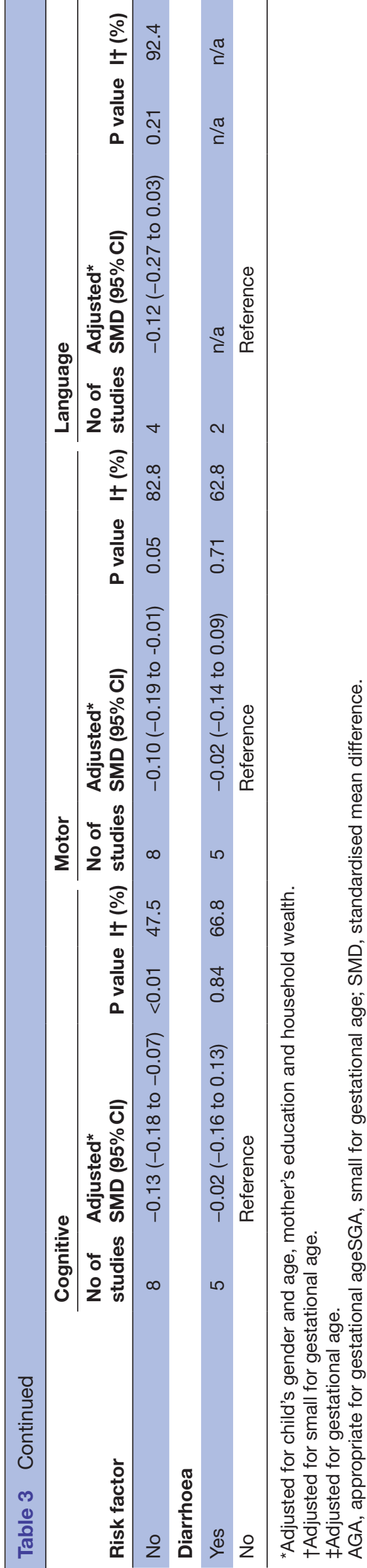

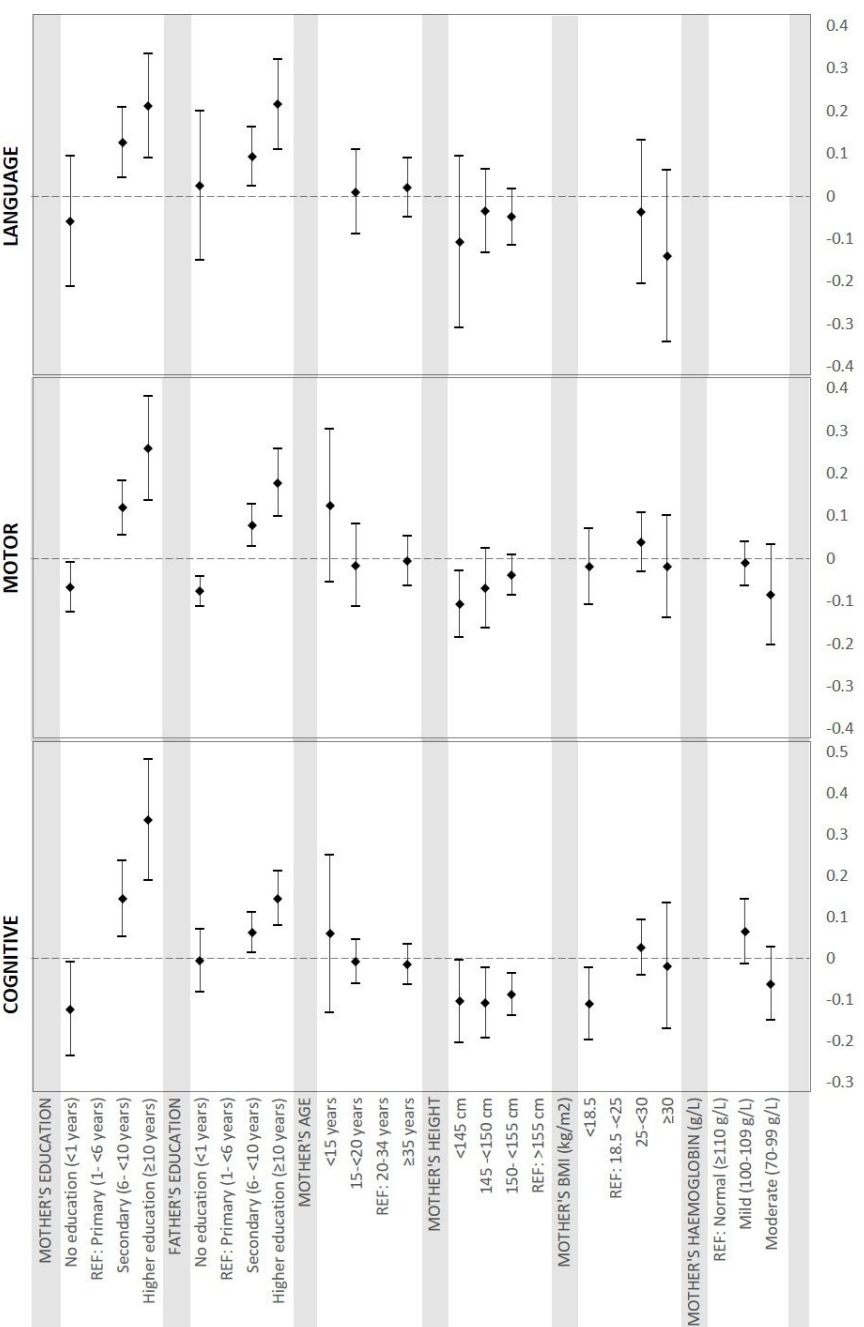

Figure 2 Pooled estimates of association between maternal factors and development.BMI, body mass index.

low maternal education can serve as a simple risk marker to target children in need of ECD intervention. ${ }^{49}$

We found significant negative associations of preterm birth with cognitive and motor development but not with language development. Meta-analyses of studies conducted in developed countries reported lower IQ (intelligence quotient) scores and cognitive functioning, ${ }^{50-52}$ along with deficits in motor, ${ }^{53}$ language ${ }^{54}$ and visual-spatial abilities $^{55}$ in preterm infants. Reduction of the intrauterine period interrupts the trajectory of neurodevelopmental processes such as synapse formation and myelination, which often leads to neurocognitive deficits. ${ }^{56}$ Although most preterm infants catch up in physical growth, ${ }^{57}$ this deficit in neurocognitive development often persists into childhood and adolescence. ${ }^{5859}$ Given the high incidence of preterm delivery in $\mathrm{LMIC}^{60}$ and the increased survival of preterm infants with medical advances, the burden of the developmental deficits caused by preterm birth in LMIC may be increasing. There are currently few interventions to prevent preterm birth $^{61}$; however, a variety of psychosocial interventions to alleviate the adverse neurodevelopmental effects of preterm birth implemented at 


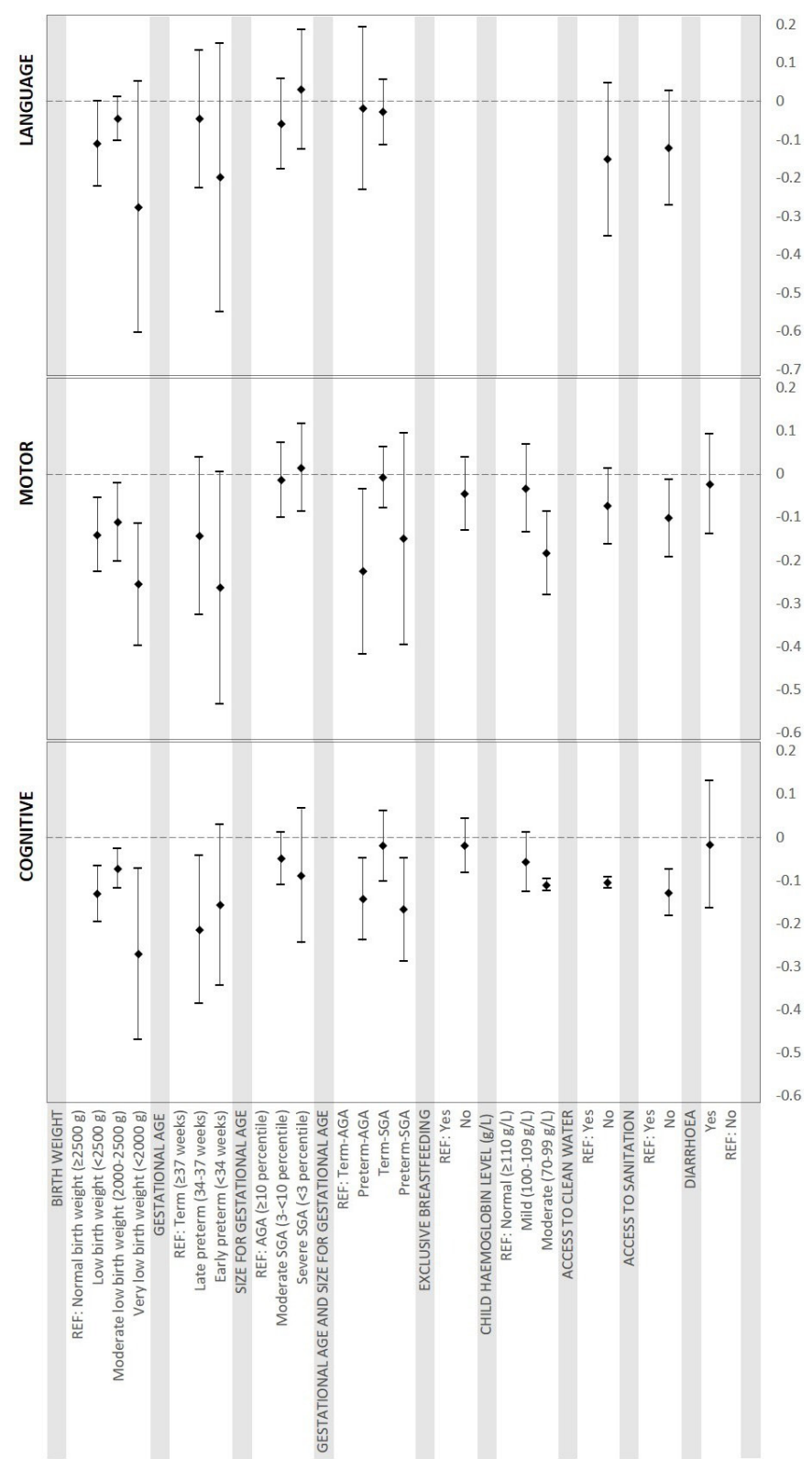

Figure 3 Pooled estimates of association between child factors and development.

different points in early childhood have shown modest short-term benefits. ${ }^{62}$

We found that fetal growth restriction, assessed via SGA, was not significantly associated with child development. This agrees with several reports from developed countries $^{63-65}$ whereas others have reported adverse effects of SGA on cognitive and motor functioning. ${ }^{32} 6667$ These disparate findings could be caused by different definitions of SGA and/or timing of the developmental assessment. Most studies from LMICs used LBW (as marker of SGA), which is also caused by prematurity, a major risk predictor of child development. There is some evidence that with adequate nutrition, the developmental deficit in SGA infants is often compensated with age, although the gap in physical growth remains. ${ }^{68}$ This finding underscores the potentially differential roles and separate causal mechanisms of effects of early life risk factors for physical and mental development. It is important to note that the effect size for SGA may be biassed downwards considering the heterogeneity in outcome and the measurement error due to the use of last menstrual period date for the estimation of gestational age in most the studies. We found significant negative associations between short maternal stature $(<145 \mathrm{~cm})$ and low BMI $(<18.5 \mathrm{~kg} / \mathrm{m} 2)^{69}$ on cognitive function, which may indicate the role of chronic malnutrition of mothers over their life course on pregnancy health and development of fetus. These are also known risk factors of SGA, ${ }^{69}$ suggesting that adverse effects of fetal growth restriction on child development are possible. Further research is needed to quantify the effects of fetal growth restriction on children's development and evaluate the effects of interventions to alleviate the negative impacts of SGA on development.

We found an adverse role of anaemia in infancy with motor and cognitive development. Prior studies reported significant effects of anaemia on cognitive, motor and socioemotional development that persisted into middle childhood during longitudinal follow-up. ${ }^{70}$ Worldwide, the predominant cause of anaemia for infants and children is iron deficiency, ${ }^{71}$ which can interfere with myelination, synapse formation and protein expression during sensitive periods of neurodevelopment. ${ }^{72}$ Meta-analyses of randomised trials of infant iron supplementation have not established an effect on child development; however, statistical power to detect effect sizes of $<0.2 \mathrm{SD}$ as our analysis predicts is limited due to few trials with large enough sample sizes. ${ }^{7374}$ In our pooled analyses, maternal anaemia during pregnancy, an important determinant of anaemia in infancy, ${ }^{75}$ was not significantly associated with children's development. We also did not find a significant association between exclusive breast feeding until 6 months of age and children's development. Nevertheless, few studies included in our pooled analyses had a sufficient number of infants who were exclusively breastfed until 6 months to allow for a well-powered analysis. Because of the multidimensional benefits of breast feeding from infection prevention to fostering mother-infant bonding and infant attachment, significant positive effects of exclusive breast feeding on child development are plausible. Meta-analyses of studies of effects of breast feeding on children's development reported significant increases in intelligence and cognitive scores ${ }^{76} 77$; however, some studies have attributed these associations entirely to the presence of confounding by socioeconomic status and stimulation at home. ${ }^{78}$

This study is among the first to report on the associations between lack of access to safe water and sanitation and child cognitive development. The burden of developmental deficit attributed to these risk factors is likely very high as a large proportion of the population in LMICs reside in unhygienic environments with limited access to safe water. The effects of poor sanitation and unsafe water on child cognitive development are potentially mediated through childhood anaemia, inflammation 
and undernutrition resulting from frequent enteric infections. ${ }^{79}$ However, in the pooled analyses, we did not find any significant adverse associations between diarrhoea and development, which is different from previously published evidence. ${ }^{23} 8081$ One potential explanation for the lack of association found in this study may be measurement error: diarrhoea is inherently complex and hard to measure; variations in the definitions of episodes as well as parental inability to correctly report diarrhoea may have led to the failure to detect potential effects of diarrhoea on cognitive, motor and language development in this study.

The strengths of this pooled study include the global coverage of the cohorts, the large sample size and uniform classifications of early life exposures and statistical analyses across studies. Nevertheless, there are also several limitations, including the lack of data on exposure to environmental neurotoxicants, maternal depression, responsive parenting behaviours, and child stimulation and early education. A recent meta-analysis determined that the potential effect of responsive stimulation on cognitive development at 2 years of age was +0.42 SD (95\% CI 0.36 to 0.48$),{ }^{82}$ which is larger than all risk factors examined in our analysis. Thus, comprehensive packages of environmental, nutrition and stimulation interventions may produce larger effect sizes than interventions targeting single risks. In addition, due to the observational nature of the studies included in this analysis, we are unable to determine a causal relationship between parental and child factors with child development. Although we have adjusted for major confounders the potential for residual confounding remains. Another limitation is that we did not perform any risk of bias assessments for observational studies. Nevertheless, each study adjusted for the same set of factors in the pooled analyses and thereby likely minimised differences in control of confounding between studies. Last, there was moderate to high levels of heterogeneity, as indicated by the $\mathrm{I}^{2}$ values, in some of our pooled estimates. The magnitude of the relationship for maternal education, prematurity, birth weight, SGA and access to water and sanitation appeared to vary by study cohort. As a result, cultural and other contextual factors may be important in determining the strength of the relationship between health and nutrition exposures with child development outcomes. Accordingly, future intervention studies should be conducted among diverse study populations as their effect may importantly differ by setting.

In summary, in a pooled study of 21 studies in LMICs, we determined that multiple risk factors classically associated with child morbidity and mortality also appear to have negative associations with cognitive, motor and language development. As a result, our study suggests that interventions that span pre-pregnancy through early and middle childhood may be necessary to provide optimal child development in LMICs. Future research should focus on determining the effectiveness of, and delivery strategies for comprehensive intervention packages to promote child development.

\section{Author affiliations}

${ }^{1}$ ICAP and Department of Epidemiology, Mailman School of Public Health, Columbia University, New York city, New York, USA

${ }^{2}$ Department of Global Health and Population, Harvard University T H Chan School of Public Health, Boston, Massachusetts, USA

${ }^{3}$ Deaprtment of Global Health and Population, and Epidemiology, Harvard University T H Chan School of Public Health, Boston, Massachusetts, USA

${ }^{4}$ Household Economics and Health System Research Unit, Schweizerisches Tropenund Public Health-Institut, Basel, Switzerland

${ }^{5}$ Harvard Graduate School of Education, Harvard University, Cambridge,

Massachusetts, USA

${ }^{6}$ Departments of Epidemiology and Environmental Health, Harvard University T H

Chan School of Public Health, Boston, Massachusetts, USA

${ }^{7}$ Department of Global Health and Social Medicine, Harvard Medical School, Boston, Massachusetts, USA

${ }^{8}$ Department of Family Medicine, Marmara University School of Medicine, Istanbul, Turkey

${ }^{9}$ Maternal and Child Health Division, ICDDR,B, Dhaka, Bangladesh

${ }^{10}$ Postgraduate Program in Epidemiology, Federal University of Pelotas, Pelotas, Brazil

${ }^{11}$ Department of Neurology, Harvard Medical School and Boston Children's Hospital, Boston, Massachusetts, USA

${ }^{12}$ Department of Pediatrics, University of Maryland School of Medicine, Baltimore, Maryland, USA

${ }^{13}$ Nutrition and Scientific Affairs, The Nature's Bounty Co, Ronkonkoma, New York, USA

${ }^{14}$ Brown University School of Public Health, Providence, Rhode Island, USA

${ }^{15}$ Maternal and Newborn Health, Liverpool School of Tropical Medicine, Liverpool, UK

${ }^{16}$ Department of Maternal and Child Health, Shoklo Malaria Research Unit, Mae Sot, Thailand

${ }^{17}$ Office of Population Studies Foundation, Inc, University of San Carlos, Cebu City, Philippines

${ }^{18}$ Center for Nutrition, Boston Children's Hospital, Boston, Massachusetts, USA

${ }^{19}$ Community Health Sciences, School of Public Health, University of California,

Berkeley, California, USA

${ }^{20}$ Women and Children's Health, University of Liverpool, Institute of Translational

Medicine, Liverpool, UK

${ }^{21}$ College of Population Health, University of New Mexico, Albuquerque, New Mexico, USA

${ }^{22}$ Department of Epidemiology, University of Michigan School of Public Health, Ann Arbor, Michigan, USA

${ }^{23}$ Poverty Health and Nutrition Division, International Food Policy Research Institute, Washington, DC, USA

${ }^{24}$ Department of Anthropology, Northwestern University, Evanston, Illinois, USA

${ }^{25}$ Regional Centre for Child and Youth Mental Health and Child Welfare, NORCE

Norwegian Research Center, Bergen, Norway

${ }^{26}$ Department of Nutrition, Harvard University T H Chan School of Public Health, Boston, Massachusetts, USA

${ }^{27}$ Department of Pediatrics and Child Health, Muhibili University of Health and Allied Sciences, Dar es Salaam, Tanzania

${ }^{28}$ Ifakara Health Institute, Dar es Salam, Tanzania

${ }^{29}$ Departamento de Medicina Preventiva, Faculdade de Medicina FMUSP,

Universidade de São Paulo, Sao Paulo, Brasil

${ }^{30}$ Children's Hospital Oakland Research Institute, UCSF Benioff Children's Hospital, Oakland, California, USA

${ }^{31}$ Faculty of Tropical Medicine, Mahidol University, Shoklo Malaria Research Unit, Mahidol-Oxford Tropical Medicine Research Unit, Mae Sot, Thailand

${ }^{32}$ Centre for Tropical Medicine and Global Health, Nuffield Department of Medicine, University of Oxford, Oxford, UK

${ }^{33}$ Pediatrics and Child Health, Aga Khan Medical University, Karachi, Pakistan

${ }^{34}$ Department of Collective Health, Universidade Federal da Bahia, Salvador, Brazil

${ }^{35}$ Department of Public Health, Marmara University School of Medicine, Istanbul,

Turkey

${ }^{36}$ Department of Immunology and Infectious Disease, Harvard University T H Chan School of Public Health, Boston, Massachusetts, USA

${ }^{37}$ Department of Nutritional Sciences, Oklahoma State University College of Human Environmental Sciences, Stillwater, Oklahoma, USA 
${ }^{38}$ Department of Laboratory Medicine, Sykehuset Innlandet Helseforetaket, Brumunddal, Norway

${ }^{39}$ Centre for Health Research and Development, Society for Applied Studies, New Delhi, India

${ }^{40}$ Division of Research on Public Health, National Institute of Perinatology, Mexico City, Mexico

${ }^{41}$ Nutrition and Clinical Services Division, ICDDR, B, Dhaka, Bangladesh

${ }^{42}$ MRC Centre for Environment and Health, School of Public Health, Imperial College

London, London, UK

${ }^{43}$ Deaprtment of Global Health and Population, Epidemiology, and Nutrition, Harvard University T H Chan School of Public Health, Boston, Massachusetts, USA

Contributors AS conceptualised the study, conducted the literature review, data analysis and drafted the manuscript. CRS and WF conceptualised the study and drafted the manuscript. GD, GF, DCM, MCSF and ME provided critical input in the study design, interpretation of results and reviewed the manuscript. ZZ participated in literature review and data analysis for the study. MA, SEA, AJDB, DB, MMB, AB, JMB, NvdB, VC, PD, CD, LCHF, MG, JH, AJH, SH, MH, CK, IK, LL, KM, HM, AM, CM, RM, AR, DaS, LS, DiS, RS, BS, TAS, ST, M-MT-R, FT and AKY contributed data to the study, analysed data and reviewed the manuscript. All authors had full access to their respective study data and to all statistical reports and tables of the pooled analyses and can take responsibility for the integrity of the data and accuracy of data analyses. The corresponding author attests that all listed authors meet authorship criteria and that no others meeting the criteria have been omitted.

Funding This study was supported by Grand Challenges Canada under the Saving Brains program (grant \# 0073-03) to Harvard T H Chan School of Public Health. AS was supported by National Institute of Allergy and Infectious Diseases of the National Institutes of Health under award number T32Al114398.

Competing interests None declared.

Patient consent for publication Not required.

Ethics approval The pooled study was approved by the Harvard T H Chan School of Public Health (IRB16-0256).

Provenance and peer review Not commissioned; externally peer reviewed.

Data availability statement Data may be obtained from a third party and are not publicly available.

Open access This is an open access article distributed in accordance with the Creative Commons Attribution Non Commercial (CC BY-NC 4.0) license, which permits others to distribute, remix, adapt, build upon this work non-commercially, and license their derivative works on different terms, provided the original work is properly cited, appropriate credit is given, any changes made indicated, and the use is non-commercial. See: http://creativecommons.org/licenses/by-nc/4.0/.

ORCID iD

Tor A Strand http://orcid.org/0000-0002-4038-151X

\section{REFERENCES}

1. Black MM, Walker SP, Fernald LCH, et al. Early childhood development coming of age: science through the life course. Lancet 2017;389:77-90.

2. Lu C, Black MM, Richter LM. Risk of poor development in young children in low-income and middle-income countries: an estimation and analysis at the global, regional, and country level. Lancet Glob Health 2016;4:e916-22.

3. McCoy DC, Peet ED, Ezzati M, et al. Early childhood developmental status in low- and middle-income countries: national, regional, and global prevalence estimates using predictive modeling. PLoS Med 2016;13:e1002034.

4. Knudsen El. Sensitive periods in the development of the brain and behavior. J Cogn Neurosci 2004;16:1412-25.

5. Shonkoff JP, Boyce WT, Neuroscience MBS. Molecular biology, and the childhood roots of health disparities: building a new framework for health promotion and disease prevention. JAMA 2009;301:2252-9.

6. Peet ED, McCoy DC, Danaei G, et al. Early childhood development and schooling attainment: longitudinal evidence from British, Finnish and Philippine birth cohorts. PLoS One 2015;10:e0137219.

7. Case A, Paxson C. Stature and status: height, ability, and labor market outcomes. J Polit Econ 2008;116:499-532.
8. Engle PL, Black MM, Behrman JR, et al. Strategies to avoid the loss of developmental potential in more than 200 million children in the developing world. Lancet 2007;369:229-42.

9. Grantham-McGregor S, Cheung YB, Cueto S, et al. Developmental potential in the first 5 years for children in developing countries. Lancet 2007;369:60-70.

10. Fink G, Peet E, Danaei G, et al. Schooling and wage income losses due to early-childhood growth faltering in developing countries: national, regional, and global estimates. Am J Clin Nutr 2016;104:104-12.

11. UN. The 2030 agenda for sustainable development. in: United nations, ED. New York: United Nations, 2015

12. Danaei G, Andrews KG, Sudfeld CR, et al. Risk factors for childhood stunting in 137 developing countries: a comparative risk assessment analysis at global, regional, and country levels. PLoS Med 2016;13:e1002164.

13. Walker SP, Wachs TD, Meeks Gardner J, et al. Child development: risk factors for adverse outcomes in developing countries. The Lancet 2007;369:145-57.

14. Walker SP, Wachs TD, Grantham-McGregor S, et al. Inequality in early childhood: risk and protective factors for early child development. The Lancet 2011;378:1325-38.

15. Prado EL, Abbeddou S, Yakes Jimenez E, et al. Effects of an intervention on infant growth and development: evidence for different mechanisms at work. Matern Child Nutr 2016.

16. Sudfeld CR, Charles McCoy D, Danaei G, et al. Linear growth and child development in low- and middle-income countries: a metaanalysis. Pediatrics 2015;135:e1266-75.

17. World Health Organization. Nurturing care for early childhood development: a framework for helping children survive and thrive to transform health and human potential, 2018.

18. DerSimonian R, Laird N. Meta-Analysis in clinical trials. Control Clin Trials 1986;7:177-88.

19. Black MM, Baqui AH, Zaman K, et al. Iron and zinc supplementation promote motor development and exploratory behavior among Bangladeshi infants. Am J Clin Nutr 2004;80:903-10.

20. Tofail F, Persson Lars Åke, El Arifeen S, et al. Effects of prenatal food and micronutrient supplementation on infant development: a randomized trial from the maternal and infant nutrition interventions, Matlab (MINIMat) study. Am J Clin Nutr 2008;87:704-11.

21. Tofail F, Hamadani JD, Ahmed AZT, et al. The mental development and behavior of low-birth-weight Bangladeshi infants from an urban low-income community. Eur J Clin Nutr 2012;66:237-43.

22. Taneja S, Bhandari N, Bahl R, et al. Impact of zinc supplementation on mental and psychomotor scores of children aged 12 to 18 months: a randomized, double-blind trial. J Pediatr 2005;146:506-11.

23. Kvestad I, Taneja S, Hysing M, et al. Diarrhea, stimulation and growth predict neurodevelopment in young North Indian children. PLoS One 2015;10:e0121743.

24. Yousafzai AK, Rasheed MA, Rizvi A, et al. Effect of integrated responsive stimulation and nutrition interventions in the lady health worker programme in Pakistan on child development, growth, and health outcomes: a cluster-randomised factorial effectiveness trial. Lancet 2014;384:1282-93

25. Duazo P, Avila J, Kuzawa CW. Breastfeeding and later psychosocial development in the Philippines. Am J Hum Biol 2010;22:725-30.

26. Villegas L, McGready R, Htway M, et al. Chloroquine prophylaxis against vivax malaria in pregnancy: a randomized, double-blind, placebo-controlled trial. Trop Med Int Health 2007;12:209-18.

27. Shapiro RL, Kitch D, Ogwu A, et al. Hiv transmission and 24-month survival in a randomized trial of HAART to prevent MTCT during pregnancy and breastfeeding in Botswana. AIDS 2013;27:1911-20.

28. Bogale A, Abebe $Y$, Stoecker BJ, et al. lodine status and cognitive function of women and their five year-old children in rural Sidama, southern Ethiopia. East Afr J Public Health 2009;6:296-9.

29. Gladstone M, White S, Kafulafula G, et al. Post-neonatal mortality, morbidity, and developmental outcome after ultrasound-dated preterm birth in rural Malawi: a community-based cohort study. PLoS Med 2011;8:e1001121.

30. McDonald CM, Manji KP, Kupka R, et al. Stunting and wasting are associated with poorer psychomotor and mental development in HIV-exposed Tanzanian infants. J Nutr 2013;143:204-14.

31. Manji KP, McDonald CM, Kupka R, et al. Effect of multivitamin supplementation on the neurodevelopment of HIV-exposed Tanzanian infants: a randomized, double-blind, placebo-controlled clinical trial. J Trop Pediatr 2014;60:279-86.

32. Sudfeld CR, McCoy DC, Fink G, et al. Malnutrition and its determinants are associated with suboptimal cognitive, communication, and motor development in Tanzanian children. $J$ Nutr 2015;145:2705-14. 
33. Locks LM, Manji KP, McDonald CM, et al. Effect of zinc and multivitamin supplementation on the growth of Tanzanian children aged 6-84 wk: a randomized, placebo-controlled, double-blind trial. Am J Clin Nutr 2016.

34. Santos IS, Barros AJ, Matijasevich A, et al. Cohort profile: the 2004 Pelotas (Brazil) birth cohort study. Int J Epidemiol 2011;40:1461-8.

35. Santos DN, Assis AMO, Bastos ACS, et al. Determinants of cognitive function in childhood: a cohort study in a middle income context. BMC Public Health 2008;8:202.

36. Fernald LCH, Hidrobo M. Effect of Ecuador's cash transfer program (Bono de Desarrollo Humano) on child development in infants and toddlers: A randomized effectiveness trial. Soc Sci Med 2011;72:1437-46.

37. Handal AJ, Harlow SD, Breilh J, et al. Occupational exposure to pesticides during pregnancy and neurobehavioral development of infants and toddlers. Epidemiology 2008;19:851-9.

38. Braun JM, Hoffman E, Schwartz J, et al. Assessing windows of susceptibility to lead-induced cognitive deficits in Mexican children. Neurotoxicology 2012;33:1040-7.

39. Akman M, Cebeci D, Okur V, et al. The effects of iron deficiency on infants' developmental test performance. Acta Paediatr 2004;93:1391-6.

40. Patra K, Greene MM, Patel AL, et al. Maternal education level predicts cognitive, language, and motor outcome in preterm infants in the second year of life. Am J Perinatol 2016;33:738-44.

41. Vollmer S, Bommer C, Krishna A, et al. The association of parental education with childhood undernutrition in low- and middle-income countries: comparing the role of paternal and maternal education. Int J Epidemiol 2016.

42. Pancsofar N, Vernon-Feagans L. Fathers' early contributions to children's language development in families from low-income rural communities. Early Child Res Q 2010;25:450-63.

43. Carneiro P, Meghir C, Parey M, et al. Maternal education, home environments, and the development of children and adolescents. $J$ Eur Econ Assoc 2013;11:123-60.

44. Fein SB, Labiner-Wolfe J, Scanlon KS, et al. Selected complementary feeding practices and their association with maternal education. Pediatrics 2008;122(Suppl 2):S91-7.

45. Simkhada B, Teijlingen ERvan, Porter M, et al. Factors affecting the utilization of antenatal care in developing countries: systematic review of the literature. J Adv Nurs 2008;61:244-60.

46. Di Cesare M, Sabates R, Lewin KM. A double prevention: how maternal education can affect maternal mental health child health and child cognitive development 2013;4.

47. Makoka D, Masibo PK. Is there a threshold level of maternal education sufficient to reduce child undernutrition? Evidence from Malawi, Tanzania and Zimbabwe. BMC Pediatr 2015;15:96.

48. de Souza N, Sardessai V, Joshi K, et al. The determinants of compliance with an early intervention programme for high-risk babies in India. Child Care Health Dev 2006;32:63-72.

49. Barros AJD, Matijasevich A, Santos IS, et al. Child development in a birth cohort: effect of child stimulation is stronger in less educated mothers. Int J Epidemiol 2010;39:285-94.

50. de Jong M, Verhoeven M, van Baar AL. School outcome, cognitive functioning, and behaviour problems in moderate and late preterm children and adults: a review. Semin Fetal Neonatal Med 2012;17:163-9.

51. McGowan JE, Alderdice FA, Holmes VA, et al. Early childhood development of late-preterm infants: a systematic review. Pediatrics 2011;127:1111-24.

52. Aarnoudse-Moens CSH, Weisglas-Kuperus N, van Goudoever JB, et al. Meta-Analysis of neurobehavioral outcomes in very preterm and/or very low birth weight children. Pediatrics 2009;124:717-28.

53. de Kieviet JF, Piek JP, Aarnoudse-Moens CS, et al. Motor development in very preterm and very low-birth-weight children from birth to adolescence. JAMA 2009;302:2235-42.

54. Mulder H, Pitchford NJ, Hagger MS, et al. Development of executive function and attention in preterm children: a systematic review. Dev Neuropsychol 2009;34:393-421.

55. Geldof CJA, van Wassenaer AG, de Kieviet JF, et al. Visual perception and visual-motor integration in very preterm and/or very low birth weight children: a meta-analysis. Res Dev Disabil 2012;33:726-36.

56. Counsell SJ, Boardman JP. Differential brain growth in the infant born preterm: current knowledge and future developments from brain imaging. Semin Fetal Neonatal Med 2005;10:403-10.

57. Finken MJJ, Dekker FW, de Zegher F, et al. Long-Term height gain of prematurely born children with neonatal growth restraint: parallellism with the growth pattern of short children born small for gestational age. Pediatrics 2006;118:640-3.
58. de KIEVIET JF, Zoetebier L, van ELBURG RM, et al. Brain development of very preterm and very low-birthweight children in childhood and adolescence: a meta-analysis. Dev Med Child Neurol 2012;54:313-23.

59. Mikkola K, Ritari N, Tommiska V, et al. Neurodevelopmental outcome at 5 years of age of a national cohort of extremely low birth weight infants who were born in 1996-1997. Pediatrics 2005;116:1391-400.

60. Blencowe $\mathrm{H}$, Cousens $\mathrm{S}$, Oestergaard MZ, et al. National, regional, and worldwide estimates of preterm birth rates in the year 2010 with time trends since 1990 for selected countries: a systematic analysis and implications. Lancet 2012;379:2162-72.

61. Simmons LE, Rubens CE, Darmstadt GL, et al. Preventing preterm birth and neonatal mortality: exploring the epidemiology, causes, and interventions. Semin Perinatol 2010;34:408-15.

62. Guralnick MJ. Preventive interventions for preterm children: effectiveness and developmental mechanisms. J Dev Behav Pediatr 2012;33:352-64

63. Nögel SC, Deiters L, Stemmler M, et al. Preterm small-forgestational age children: predictive role of gestational age for mental development at the age of 2years. Brain Dev 2015;37:394-401.

64. Bickle Graz M, Tolsa J-F, Fischer Fumeaux CJ. Being small for gestational age: does it matter for the neurodevelopment of premature infants? a cohort study. PLoS One 2015;10:e0125769.

65. Tanis JC, van der Ree $\mathrm{MH}$, Roze $\mathrm{E}$, et al. Functional outcome of very preterm-born and small-for-gestational-age children at school age. Pediatr Res 2012;72:641-8.

66. Arcangeli T, Thilaganathan B, Hooper R, et al. Neurodevelopmental delay in small babies at term: a systematic review. Ultrasound Obstet Gynecol 2012;40:267-75.

67. Savchev S, Sanz-Cortes M, Cruz-Martinez R, et al. Neurodevelopmental outcome of full-term small-for-gestational-age infants with normal placental function. Ultrasound Obstet Gynecol 2013;42:201-6.

68. Brandt I, Sticker EJ, Lentze MJ. Catch-Up growth of head circumference of very low birth weight, small for gestational age preterm infants and mental development to adulthood. J Pediatr 2003;142:463-70.

69. McCowan L, Horgan RP. Risk factors for small for gestational age infants. Best Pract Res Clin Obstet Gynaecol 2009;23:779-93.

70. Lozoff B. Iron deficiency and child development. Food Nutr Bull 2007;28(4 Suppl):S560-71.

71. McLean E, Cogswell M, Egli I, et al. Worldwide prevalence of anaemia, who vitamin and mineral nutrition information system, 1993-2005. Public Health Nutr 2009;12:444-54.

72. Beard JL, Felt B, Schallert T, et al. Moderate iron deficiency in infancy: biology and behavior in young rats. Behav Brain Res 2006;170:224-32.

73. Pasricha S-R, Hayes E, Kalumba K, et al. Effect of daily iron supplementation on health in children aged 4-23 months: a systematic review and meta-analysis of randomised controlled trials. Lancet Glob Health 2013;1:e77-86.

74. Sachdev HPS, Gera T, Nestel P. Effect of iron supplementation on mental and motor development in children: systematic review of randomised controlled trials. Public Health Nutr 2005;8:117-32.

75. Koura GK, Ouedraogo S, Le Port A, et al. Anaemia during pregnancy: impact on birth outcome and infant haemoglobin level during the first 18 months of life. Trop Med Int Health 2012;17:283-91.

76. Anderson JW, Johnstone BM, Remley DT. Breast-Feeding and cognitive development: a meta-analysis. Am J Clin Nutr 1999;70:525-35

77. Horta BL, Loret de Mola C, Victora CG. Breastfeeding and intelligence: a systematic review and meta-analysis. Acta Paediatr 2015;104:14-19.

78. Walfisch A, Sermer C, Cressman A, et al. Breast milk and cognitive development -the role of confounders: a systematic review. BMJ Open 2013;3:e003259.

79. Ngure FM, Reid BM, Humphrey JH, et al. Water, sanitation, and hygiene (wash), environmental enteropathy, nutrition, and early child development: making the links. Ann N Y Acad Sci 2014;1308:118-28.

80. Niehaus MD, Moore SR, Patrick PD, et al. Early childhood diarrhea is associated with diminished cognitive function 4 to 7 years later in children in a northeast Brazilian shantytown. Am J Trop Med Hyg 2002:66:590-3.

81. Petri WA, Miller M, Binder HJ, et al. Enteric infections, diarrhea, and their impact on function and development. $J$ Clin Invest 2008;118:1277-90.

82. Aboud FE, Yousafzai AK. Global health and development in early childhood. Annu Rev Psychol 2015;66:433-57. 